\title{
The impact of the long-lasting socioeconomic crisis in Greece
}

\author{
Stelios Stylianidis ${ }^{1}$ and Kyriakos Souliotis ${ }^{2}$
}

${ }^{1}$ Panteion University of Social and Political Sciences, and Association for Regional Development and Mental Health (EPAPSY), Aths, Grental Health stylianidis.st@gmail.com ${ }^{2}$ Faculty of Social and Political Sciences, University of Peloponnese, Corinth, Greece

Conflicts of interest None.

doi:10.1192/bji.2017.31

(c) The Authors 2018. This is an Open Access article, distributed under the terms of the Creative Commons Attribution-

NonCommercial-NoDerivatives licence (http://creativecommons. . org/licenses/by-nc-nd/4.0/), whic permits non-commercial re-use, distribution, and reproduction in any medium, provided the original work is unaltered and is properly cited. The written permission of Cambridge University Press must University Press must be obtained for or in order to create a derivative work.
Since 2009, Greece has experienced a long-lasting socioeconomic crisis that has had substantial consequences on the health and mental health of the population.

Unemployment, financial hardship and income loss constitute the hallmarks of the socioeconomic landscape. Consequently, a substantial decline in health and mental health has been documented. Converging evidence corroborates a deterioration of self-rated health, an alarming rise in suicide rates and a gradual increase in the prevalence of major depression. Concomitantly, the healthcare system is on the verge of collapse and the mental healthcare system is incapable of addressing the emerging needs. Therefore, a multifaceted and concerted effort is urgently needed to mitigate the mental health effects of the recession.

\section{Socioeconomic climate}

In 2009 Greece entered a period of lasting recession and austerity with wide-ranging socioeconomic, demographic and political implications. This has led to sharp rises in unemployment rates, precarious work regimes, rapid increases in poverty level, dramatic increases in the number of uninsured citizens, substantial income loss, widened income inequality, exacerbation of the demographic problem, disruption of social cohesion, political instability, and migration and refugee issues. In particular, unemployment rates rocketed from $7.8 \%$ in 2008 to $24.9 \%$ in 2015 and $23.1 \%$ in December 2016 (Eurostat, 2017). Concomitantly, the proportion of the population that is at risk of poverty or social exclusion rose from $28.1 \%$ in 2008 to $36 \%$ in 2014 and $35.7 \%$ in 2015 (Hellenic Statistical Authority, 2015). Similarly, a survey by the Hellenic Confederation of Professionals, Craftsmen and Merchants has documented substantial income loss for $93.7 \%$ of households since the outset off the crisis, and $75.3 \%$ of them reported further reductions between 2015 and 2016. It is noteworthy that the increasing income inequality was in favour of the high-income sectors of the population (Hellenic Confederation of Professionals, Craftsmen and Merchants, 2015). The demographic problem is due to lower birth rates, causing a negative natural population change, coupled with elevated (net) migration (Eurostat, 2015). Consequently, the sustainability of the social health insurance and pension system is at stake. Arguably, this socioeconomic climate has incurred adverse consequences on the health of the population and healthcare system.

\section{Health and the healthcare system}

The health effects of the financial crisis have been the topic of a vociferous debate in Greece. On the one hand, Kentikelenis and colleagues have argued there has been a gradual deterioration of health; however, other researchers have questioned their conclusions (for a commentary on the debate, see McKee \& Stuckler, 2016). At the same time, growing evidence indicates a negative impact of the crisis on self-rated health, both over time and in comparison with other countries (Hessel et al, 2014). Moreover, during 20092011 there were elevated rates of morbidity and mortality due to certain large-scale epidemics, including an outbreak of West Nile virus infections, malaria and a major outbreak of HIV among people who inject drugs (Bonovas \& Nikolopoulos, 2012). This decline in health can be largely attributed to the scarcity of preventive public health measures that could have contained the spread of these epidemics, as well as to the dismantling of healthcare services.

In the wake of the economic downturn, the national health system had already been in a state of crisis; however, the recession has brought it close to collapse. Curbing of public health expenditures (by 25\% during 2008-2012), shortage of health professionals, reductions in their salaries, pension cuts, decreases in the procurement of medical supplies, rapid reforms in the pharmaceutical and social insurance sectors and inadequate primary healthcare services have been recorded (Simou \& Koutsogeorgou, 2014). Concomitantly, converging evidence supports a marked increase in unmet health needs (Zavras et al. 2016). In $2015,86 \%$ of the population was covered by public health insurance, compared with $100 \%$ in 2008, with the long-term unemployed being the ones who were most affected (OECD, 2016). Therefore, in 2016 the 'poverty booklet' was introduced to address poor and uninsured people who had exhausted their social insurance by allowing them to have free access to public hospitals, medical services and pharmaceuticals. Furthermore, the Health Outcomes Patient Environment study has revealed substantial barriers to care, with one out of four patients with rheumatoid arthritis facing difficulty in accessing their physician and one out of two patients 
struggling to get hold of their medication (Souliotis et al, 2013). This is also observed in other therapeutic categories despite the fact that Greece has the highest physician/population ratio among EU countries. Laliotis et al (2016) have demonstrated a sharp rise in deaths due to adverse events during medical treatment since the outset of the recession; thus substantiating the close link between quality of care and health outcomes in Greece amid the crisis. Additionally, suicide mortality has been on the rise.

\section{Mental health and the mental healthcare system}

The impact of the economic crisis on the suicide rate has caused a lively debate in the country; recent evidence indicates that both the recession and the accompanying austerity measures have triggered a $35 \%$ increase in suicide rates (Rachiotis et al, 2015). Similarly, a series of repeated nationwide crosssectional surveys by the University Mental Health Research Institute suggests that the crisis has had a marked impact on the prevalence of affective disorders (Economou et al, 2016). Specifically, the 1 -month prevalence of major depression rose from $3.3 \%$ in 2008 , to $6.8 \%$ in $2009,8.2 \%$ in 2011 and $12.3 \%$ in 2013 . On the contrary, the prevalence of suicide followed an upward course until 2011 and declined thereafter: prevalence of suicidal ideation was $2.4 \%$ in $2008,5.2 \%$ in $2009,6.7 \%$ in 2011 and $2.6 \%$ in 2013 (Economou et al, 2016). This pattern concurs with international findings suggesting that suicide constitutes an acute response to the onset of the crisis; whereas depression involves a prolonged course of symptoms prior to reaching a clinical manifestation (Hong et al, 2011).

Concerning the risk factors for major depression and suicidality, both unemployment and financial hardship were found to exert a statistically significant and independent influence on the prevalence of both constructs in 2013. Interestingly, the effect of unemployment and hardship on suicidality was retained, even after controlling for the effect of major depression. Therefore, suicidality cannot be explained solely by the presence of mental disorders. Rather, some suicides can be ascribed to social causes ('recession-led' suicides, Economou et al, 2016).

Despite the emerging mental health needs of the population, existing mental health services have downsized their operations and personnel and public funding for mental health has been reduced by $20 \%$ between 2010 and 2011, and by additional 55\% between 2011 and 2012 (Anagnostopoulos \& Soumaki, 2012). Notably, a heightened proportion of compulsory admissions has been recorded amid the recession (i.e. 57.4\%, Stylianidis et al. 2017) and this figure is expected to rise further in the foreseeable future.

\section{Conclusions and lessons learned from the Greek crisis}

Growing evidence substantiates that the socioeconomic crisis has incurred adverse effects on the health of the Greek population and has produced significant mental distress. Simultaneously, diverse factors related to the economic crisis - e.g. unemployment, declining incomes, financial deprivation, debts, declining social economic status and social inequalities - are closely linked to the emerging mental health problems.

In addition, this persisting situation has highlighted several insufficiencies and structural dysfunctions within the health system, as evidenced by its difficulty to respond to the increasing demands for mental healthcare, both in terms of access to care and provision of minimally adequate treatment. From a public health perspective, structural issues such as legal, administrative and financial barriers to access to healthcare; the degree of resilience of a health system; migration and refugee policies; asylum seekers; and social cohesion in a given community reveal existing vulnerabilities and create new ones (Silva et al, 2015). The complexity of the issue is evident and the multifaceted approach required to address existing problems is underscored.

However, actions and innovative initiatives have been implemented to deal with this enormous pressure. The government has recently launched the first phase of the social solidarity income (SSI) (Minimum Income Scheme) and has introduced legal provisions for the establishment of community centres which are expected, among other things, to complement the municipal social service and to support them in the implementation of the SSI (Ziomas et al, 2016). In particular, the objective of community centres is to support municipalities in the implementation of social policy measures and initiatives at the local level as well as in the development of a local point for reception, service provision and liaison with citizens (with all social programs and services available at the local level). These centres are expected to operate as nodes that interconnect locally available social services, primary healthcare units, mental health services and family physicians.

Despite this initiative, which is yet to be implemented and evaluated, there is no political will for the formulation of a national action plan that would mitigate the mental health effects of the financial crisis. Existing solidarity actions emanate solely from municipalities, the orthodox church, non-governmental organisations and include social groceries, free access out-patient medical services, social pharmacies, social firms within the context of solidarity and social economy, food saving organizations and intermediary non-profit organizations creating sustainable networks of solidarity (http://www.boroume.gr, http:// desmos.org), hostels and sheltered apartments for homeless. More specifically, in the realm of mental health an innovative program called 'Citizens Against Depression' has been implemented by the Association for Regional Development and Mental Health (EPAPSY) and the Greek Association for Mood Disorders (MAZI), 
promoting self-help groups against depression and suicidality (Economou et al. 2016). Also, psychological support is provided by non-governmental organisations (Médecins du Monde, Médecins Sans Frontières and others) in out-patient clinics and refugees camps.

\section{Recommendations}

(a) Mental Health should be assigned priority in the public health agenda. The crisis may represent an opportunity to innovate mental health policy and improve the implementation of mental health reforms.

(b) The biomedical approach in psychiatry should be revisited. It is imperative to adopt a comprehensive strategy - involving several sectors such as social services, social protection, primary healthcare and municipalities - to improve the efficiency and quality of care of the mental health system. It should be noted that according to World Health Organization recommendations, the role of primary healthcare in the management of mental health patients is crucial, especially in countries facing significant healthcare budget constraints.

(c) There should be advocacy and empowerment actions for people using mental health services (and their families) against human rights abuses and discrimination (e.g. involuntary admission to hospital).

(d) There is an urgent need to improve the leadership and governance of the mental health system; profound changes in the management and financing of mental health services should be introduced.

\section{References}

Anagnostopoulos D. \& Soumaki E. (2012) The impact of the socio-economic crisis on the mental health of children and adolescents. Psychiatriki, 23, 13-16 (in Greek).

Bonovas S. \& Nikolopoulos G. (2012) High-burden epidemics in Greece in the era of economic crisis. Early signs of a public health tragedy. Journal of Preventive Medicine and Hygiene, 53, 136-171.

Economou M., Peppou L. E., Souliotis K., et al (2016) The impact of the economic crisis in Greece: epidemiological perspective and community implications. In Social and Community Psychiatry, 1st edn (ed. S. Stylianidis), pp. 469-483. Springer International Publishing.

Eurostat (2015) Demography Report. Employment, Social Affairs \& Inclusion. Publications Office of the European Union. Available at http://ec.europa.eu/eurostat/documents/3217494/6917833/ KE-BM-15-003-EN-N.pdf/76dac490-9176-47bc-80d9-029e1d967af6 (accessed 1 May 2017)

Eurostat (2017) Euro Area Unemployment at 9.5\%. Eurostat. Available at http://ec.europa.eu/eurostat/documents/2995521/ 7963741/3-03042017-BP-EN.pdf/ d77023a5-64cb-4bf5-8181-8f4d3a0ee292 (Accessed 1 May 2017).

Hellenic Confederation of Professionals, Craftsmen and Merchants (2015) Research on Household Income and Expenses. GSEEVE.

Hellenic Statistical Authority (2015) Risk of Poverty. Research on Income and Living Conditions of Households 2014. HSA.

Hessel P., Vandoros S. \& Avendano M. (2014) The differential impact of the financial crisis on health in Ireland and Greece: a quasi-experimental approach. Public Health, 128, 911-919.

Hong J., Knapp M. \& McGuire A. (2011) Income-related inequalities in the prevalence of depression and suicidal behaviour: a 10-year trend following economic crisis. World Psychiatry, 10, 40-44.

Laliotis I., Ioannidis J. \& Stavropoulou C. (2016) Total and cause-specific mortality before and after the onset of the Greek economic crisis: an interrupted time-series analysis. The Lancet Public Health, 1, e56-e65.

McKee M. \& Stuckler D. (2016) Health effects of the financial crisis: lessons from Greece. The Lancet Public Health, 1, e40-e41.

Organisation for Economic Co-operation and Development (OECD) (2016). Health Policy in Greece. OECD. Available at http://www.oecd. org/greece/Health-Policy-in-Greece-January-2016.pdf.

Rachiotis G., Stuckler D., McKee M., et al (2015) What has happened to suicides during the Greek economic crisis? Findings from an ecological study of suicides and their determinants (2003-2012). BMJ Open, 5, e007295-e007295.

Silva M., Cardoso G., Saraceno B., et al (2015) A saúde mental e a crise económica. In Território e Saúde Mental em Tempos de Crise. [Mental health and Economic crisis. In Catchment Area and Mental Health in Times of Crisis.] 1st edn (ed. P. Santana), Imprensa da Universidade de Coimbra [Coimbra University Press].

Simou E. \& Koutsogeorgou E. (2014) Effects of the economic crisis on health and healthcare in Greece in the literature from 2009 to 2013: a systematic review. Health Policy, 115, 111-119.

Souliotis K., Papageorgiou M., Politi A., et al (2013) Barriers to accessing biologic treatment for rheumatoid arthritis in Greece: the unseen impact of the fiscal crisis-the Health Outcomes Patient Environment (HOPE) study. Rheumatology International, 34, 25-33.

Stylianidis S., Peppou L., Drakonakis N., et al (2017) Mental health care in Athens: are compulsory admissions in Greece a one-way road? International Journal of Law and Psychiatry, 52, 28-34.

Zavras D., Zavras A., Kyriopoulos I., et al (2016) Economic crisis, austerity and unmet healthcare needs: the case of Greece. BMC Health Services Research, 16, 309.

Ziomas D., Sakellis I., Theodoroulakis M., et al (2016) ESPN European Semester Report Greece 2016-2017. European Commission. 